\title{
Scientific evidence on the use of recombinant human bone morphogenetic protein-2 (rhBMP-2) in oral and maxillofacial surgery
}

\author{
Pedro Henrique Silva Gomes-Ferreira ${ }^{1} \cdot$ Roberta $_{\text {Okamoto }^{2}} \cdot$ Sabrina Ferreira $^{1}$. \\ Danila De Oliveira $^{2}$ • Gustavo Antonio Correa Momesso ${ }^{1}$ • Leonardo Perez Faverani ${ }^{1}$
}

Received: 18 August 2015 / Accepted: 17 May 2016 /Published online: 29 May 2016

(C) Springer-Verlag Berlin Heidelberg 2016

\begin{abstract}
Purpose This study aimed to identify the main indications for the use of recombinant human bone morphogenetic protein-2 (rhBMP-2) for bone repair and maintenance in the maxilla and mandible through a review of clinical trials evaluating the viability of using rhBMP-2 to delay the installation of dental implants, thus allowing satisfactory bone formation and longterm osseointegration.

Methods Literature search of the PubMed/Medline databases was performed using the following MeSH index terms"bone morphogenetic protein 2" and "dentistry". Only clinical trials necessarily published in English, related to dentistry, and focused on bone reconstruction in critical defects, postextraction alveoli, increasing the atrophic alveolar ridge, or surgery for maxillary sinus elevation were included, regardless of the age, sex, ethnicity, associated morbidities, or period of publication.

Results Of the 17 studies identified based on the search filters, 2 were excluded. Therefore, 15 studies were finally included in this review.

Conclusions Based on the results of our review, we concluded that the use of rhBMP-2 for the preservation of the alveolar ridge after tooth extraction or for increasing the local defects is safe and viable. The use of rhBMP-2/Bio-Oss ${ }^{\circledR}$ for the
\end{abstract}

Gustavo Antonio Correa Momesso gustavomomesso@gmail.com

1 Department of Surgery and Integrated Clinic, Araçatuba Dental School, Univ. Estadual Paulista (UNESP), Araçatuba, São Paulo, Brazil

2 Department of Basic Sciences, Araçatuba Dental School, Productivity scholarship (CNPQ), Univ. Estadual Paulista (UNESP), Araçatuba, São Paulo, Brazil elevation of the maxillary sinus membrane is unnecessary; however, it can improve and accelerate the maturation process in cases of guided bone regeneration in peri-implant defects. Compounds comprising rhBMP-2, allogenic bone, and plasma-rich platelet (PRP) can act as autograft substitutes in mandibular critical defects.

Keywords Atrophy $\cdot$ Biocompatible materials $\cdot$ Bone morphogenetic protein $2 \cdot$ Bone regeneration

\section{Introduction}

First described in 1965, bone morphogenetic protein (BMP) is a member of the transforming growth factor- $\beta 1$ family. Subsequent research led to the purification of bone extracts for the isolation of BMPs, which are osteoinductive proteins that stimulate endochondral and intramembranous bone formation and might lead to the differentiation of mesenchymal cells [1-5].

The bone formation ability and safety of recombinant human bone morphogenetic protein-2 (rhBMP-2) associated with absorbable collagen sponge (ACS), as well as the safety of their osteoinductive carrier components have been extensively investigated and are well known [6-9]. The application of rhBMP-2/ACS has been reported to have resulted in normal bone induction at the site of implantation - a process which involves the migration and proliferation of mesenchymal cells at the site of implantation, followed by their differentiation into osteoprogenitor cells [10].

The regeneration of any type of tissue requires the presence of the classic "tissue engineering triangle," which includes a source of cells, a signal for bone formation, and a matrix.

The implantation of rhBMP-2/ACS has been proven to be an appropriate signal for induction of bone formation in both 
lumbar vertebral [11] and tibial fractures, as well as in alveolar ridge preservation [10-13] and elevation of the maxillary sinus membrane [14-17].

It has been shown that rhBMP-2/ACS exhibits chemoattraction towards osteoprogenitor and stem cells, which serve as sources of bone-forming cells [18]. Lyophilized cancellous allograft and xenogeneic bones are commonly used as osteoconductive matrices [19]. Plateletrich plasma (PRP) is known to contain several growth factors and cell adhesion molecules (fibrin, fibronectin, and vitronectin) [10, 12], and the convergence of these three materials is an example of the formation of the "tissue engineering triangle."

Literature describes several possibilities for the application of rhBMP-2, including its widespread application in the treatment of jaw defects. However, studies are still necessary for the evaluation of the viability of this material. Therefore, this study aimed to identify scientific evidence regarding the main indications for the application of rhBMP-2 for bone repair and maintenance in the maxilla and mandible. This was accomplished through a review of clinical trials evaluating the viability of using rhBMP-2 to delay the installation of dental implants, thus allowing satisfactory bone formation and long-term osseointegration after functional loading.

Clinically, the main purpose of this review was to provide oral maxillofacial surgeons and implant specialists a current protocol of the rational use of rhBMP-2 in the reconstruction of atrophic jaws.

\section{Materials and methods}

For this literature review, we searched the PubMed/Medline databases for clinical trials involving the use of rhBMP-2, without any restriction of the time period, using the MeSH index terms "bone morphogenetic protein 2 " and "dentistry".

Limiting the search to studies related to dentistry published in English identified 243 relevant references. These results were again filtered to identify only clinical trials involving the use of rhBMP-2 for different purposes and defects, as described below:

- Critical defects

- Post-exodontic alveoli

- Increasing the atrophic alveolar ridge

- Maxillary sinus elevation

- Cleft lip and palate

Studies were included regardless of the following factors:

- Age

- Gender

- Ethnicity
- Associated comorbidities

Studies not related to the following subjects were excluded:

- Bone reconstruction

- Patients with systemic disorders that could affect the results

- In vivo studies

- In vitro studies

\section{Results}

A search of the PubMed/Medline databases for the index terms revealed 17 studies after the application of the limits and inclusion/exclusion criteria. Careful evaluation of the full texts of these studies led to the exclusion of a study related to the use of rhBMP-2 in bone defects caused by periodontal pockets [20], as well as another related to its use in maxillary bone gain for nasolabial soft tissue support [21]. Finally, 15 studies were included in this review, of which, 7 involved the use of rhBMP-2 with or without other biomaterials, apart from the evaluation of different concentrations of rhBMP-2 in the treatment of anterior atrophic maxilla and/or post-exodontics alveolus; 4 studies involved the application of rhBMP-2 in the elevation of the maxillary sinus, 2 in peri-implant defects, and 2 in defects of critical size.

The demographic and clinical characteristics evaluated in the selected studies are described in detail in Tables 1, 2, 3, 4, 5 , and 6; they included the number of patients participating in the study; sex; mean age (in years); regions of the jaw subjected to reconstruction; results of evaluation in terms of different concentrations of rhBMP-2 and/or comparison to other already acclaimed biomaterials; results of bone formation analyzed by microscopy; results of measurement of marginal bone gain/loss, either in terms of height or thickness, based on imaging findings (X-rays or computed tomography); antibody formation potential (anti-rhBMP-2, anti-bovine collagen type I, or anti-human collagen type I antibodies) evaluated through hematological examination; and implant survival rates and complications.

\section{Discussion}

Among the clinical trials reviewed in the present study, the results of those involving the use of rhBMP-2 in the treatment of atrophic ridges of the anterior maxilla or post-exodontic alveolus indicated alveolar bone maintenance, in general, regardless of the type of material used, isolated or combined use of rhBMP-2 in association with demineralized bone matrix, or type of control (blood clot or ACS only) [13, 22-26]. These 


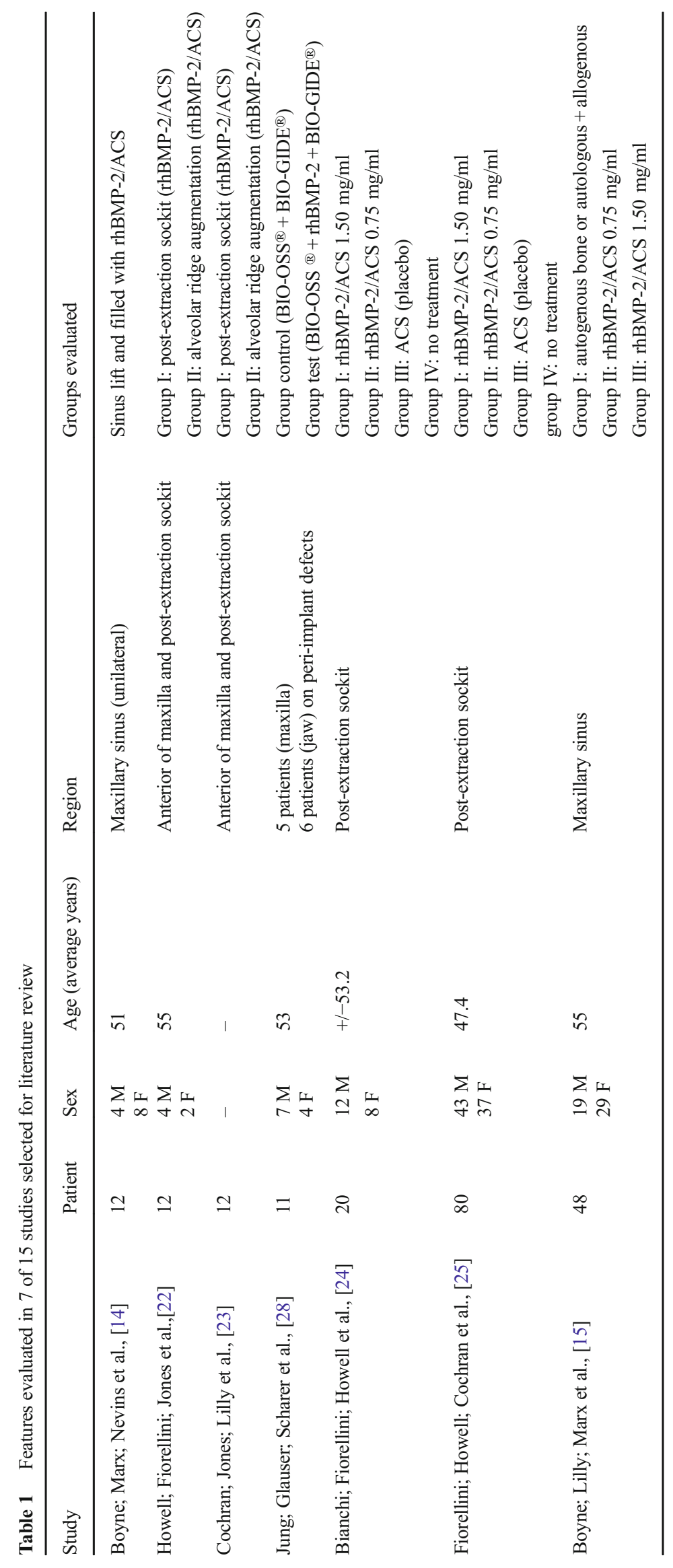




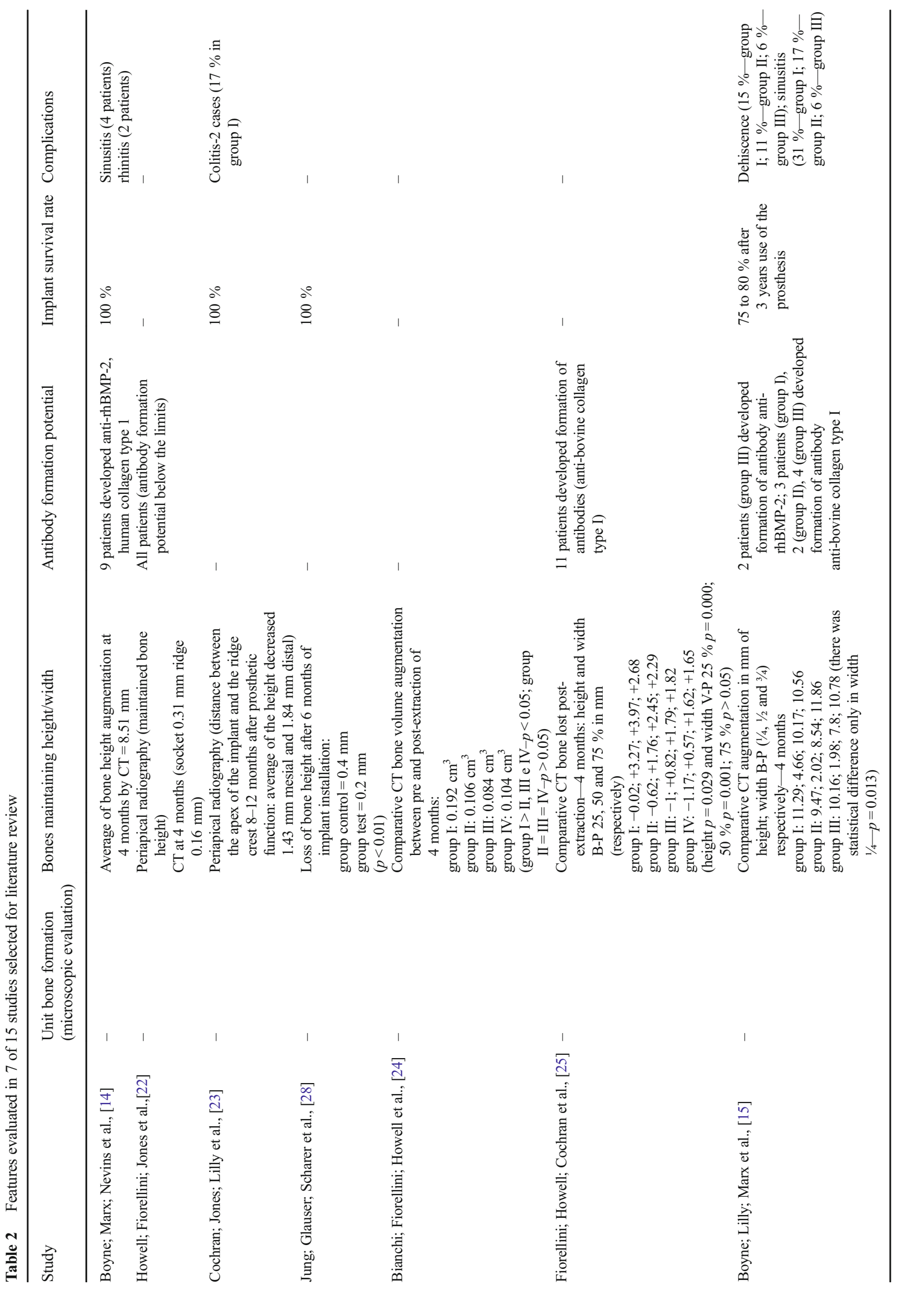


Table 3 Features evaluated in 4 of 15 studies selected for literature review

\begin{tabular}{|c|c|c|c|c|c|}
\hline Study & Patient & Sex & Age (average years) & Region & Groups valuated \\
\hline Jung; Windisch; Eggenschwiler et al., [29] & 11 & $\begin{array}{l}4 \mathrm{M} \\
7 \mathrm{~F}\end{array}$ & 53 & Peri-implant defects & $\begin{array}{l}\left.\text { Group control (BIO-OSSS }{ }^{\circledR}+\text { BIO-GIDE }^{\circledR}\right) \\
\text { Group test }\left(\text { BIO-OSS }{ }^{\circledR}+\text { rhBMP-2 }+\right. \\
\left.\quad \text { BIO-GIDE }{ }^{\circledR}\right)\end{array}$ \\
\hline Triplett; Nevins; Marx et al., [19] & 160 & $\begin{array}{l}71 \mathrm{M} \\
89 \mathrm{~F}\end{array}$ & Above 18 & Maxillary sinus & $\begin{array}{l}\text { Group control: autogenous bone } \\
\text { Group test: rhBMP- } 2\end{array}$ \\
\hline Kao; Kubota; Nevins et al., [16] & 22 & $\begin{array}{l}13 \mathrm{M} \\
9 \mathrm{~F}\end{array}$ & 50.8 & Maxillary sinus & $\begin{array}{l}\text { Group I: rhBMP-2 + } \text { Bio-Oss }^{\circledR}(80 / 20) \text {; } \\
\text { Group II: Bio-Oss }{ }^{\circledR}\end{array}$ \\
\hline Freitas; Susin; Spin-Neto et al., [26] & 24 & $\begin{array}{l}12 \mathrm{M} \\
12 \mathrm{~F}\end{array}$ & 45.5 & Anterior of maxilla & $\begin{array}{l}\text { Group control: autogenous bone } \\
\text { Group test: rhBMP-2/ACS } 1.5 \mathrm{mg} / \mathrm{ml} \\
\quad(4.2 \mathrm{mg} \text { for region })\end{array}$ \\
\hline
\end{tabular}

results also indicated the superiority of rhBMP-2 in the treatment of post-exodontic alveoli with previous vestibular bone loss [27].

Regarding the measurement of alveolar bone loss for the evaluation of the bone height (distance between the implant apex and alveolar ridge crest) and width (V-P), average bone losses of 1.84 and $1.43 \mathrm{~mm}$ in height were noted at the distal and mesial regions, respectively, within a minimum period of 3-4 months after implant installation $[22,26]$ and a maximum period of 12 months after functional rehabilitation with implant-supported prostheses; there were no statistically significant differences in efficacy between rhBMP-2 and bone substitutes or blood clot control, in the treatment of postexodontic alveoli [22, 24, 26].

It was evident from the results of the evaluated studies that the concentration of rhBMP-2 $(0.75$ or $1.5 \mathrm{mg} / \mathrm{ml})$ influenced the osteoinductive activity of BMP-2 in post-exodontic alveolar defects. Patients treated with the lowest concentration of rhBMP-2 $(0.75 \mathrm{mg} / \mathrm{ml})$ showed no statistically significant differences in terms of the bone volume, height, or width when compared to the control groups (isolated ACS or blood clot); however, the patients treated with higher concentrations of rhBMP-2 $(1.5 \mathrm{mg} / \mathrm{ml})$ exhibited significantly higher values of the same parameters when compared to the control groups $(p<0.05)$ [24]. Another study also reported higher values of V-P alveolar bone width at an rhBMP-2 concentration of $1.5 \mathrm{mg} / \mathrm{ml}$, in comparison with the other evaluated groups $(p<0.05)$ [25]. Therefore, the use of rhBMP-2 at a concentration of $1.5 \mathrm{mg} / \mathrm{ml}$ presents significant applicability in clinical dental practice for the treatment of these defects.

Therefore, at least in the treatment of post-exodontic alveolar defects and small maxillary atrophy, differences in the concentration of rhBMP-2 do not substantially influence bone repair. In these situations, the use of any bone substitute with osteoconductive properties seems to produce satisfactory results by allowing osseointegrated implant installation and long-term bone maintenance; this statement is supported by clinical investigations reporting a $100 \%$ survival rate of the installed implants $[23,26]$.
One of the challenges for guided bone regeneration is the use of biomaterials in the treatment of peri-implant defects. Exposure of implant threads because of physiological resorption after exodontia by pathological or traumatic processes is usually observed. Even in the absence of fenestration, particulate bone reconstruction is necessary if the thickness of the vestibular cortex is less than $1.5 \mathrm{~mm}[28,29]$. Regarding alveolar bone maintenance, clinical studies have reported no statistically significant differences between the efficacies of lyophilized bovine bone (Bio-Oss ${ }^{\circledR}$ ) and bovine collagen membrane (Bio-Gide ${ }^{\circledR}$ ) in the treatment of peri-implant defects, regardless of their association with rhBMP-2.

In periapical radiographic images acquired 6 months after implant installation [28] and after 3 and 5 years of prosthetic rehabilitation [29], the loss of neoformed bone in the periimplant defects was minimal, with no statistically significant differences between the two treatment groups (Bio-Oss ${ }^{\circledR}$ vs. Bio-Oss $\left.{ }^{\circledR} / \mathrm{rhBMP}-2\right)$. Therefore, in such defects, only osteoconductive bone substitutes are indicated, and supplementation with rhBMP-2 may be dispensed with.

Another area widely discussed in literature is the use of biomaterials for the elevation of the maxillary sinus membrane in order to increase the bone height in the posterior maxilla. Because of the physiological characteristic of the maxillary sinus to keep expanding during an individual's life, it is common to observe maxillary sinus pneumatization with decreased alveolar ridge height following exodontia of the upper posterior teeth. Surgery for sinus membrane elevation is indicated in cases where the residual ridge height is $5 \mathrm{~mm}$ or less [17].

In this context, several studies have reported that the use of rhBMP-2/ACS is highly favorable for the gain and maintenance of bone height in osseointegrated implants [14-16, 19]. The results of CT analysis, with a minimum follow-up period of 4 months, showed an increase of $8.51 \mathrm{~mm}$ in bone height with rhBMP-2 [14]. Another study reported that rhBMP-2 $(1.5 \mathrm{mg} / \mathrm{ml})$ produced results similar to those with autogenous bone graft, increasing the bone width to $1 / 4$ th the bone height reached after sinus membrane elevation $(p=0.013)$ [15]. In another study, based on the results of CT evaluation of the 


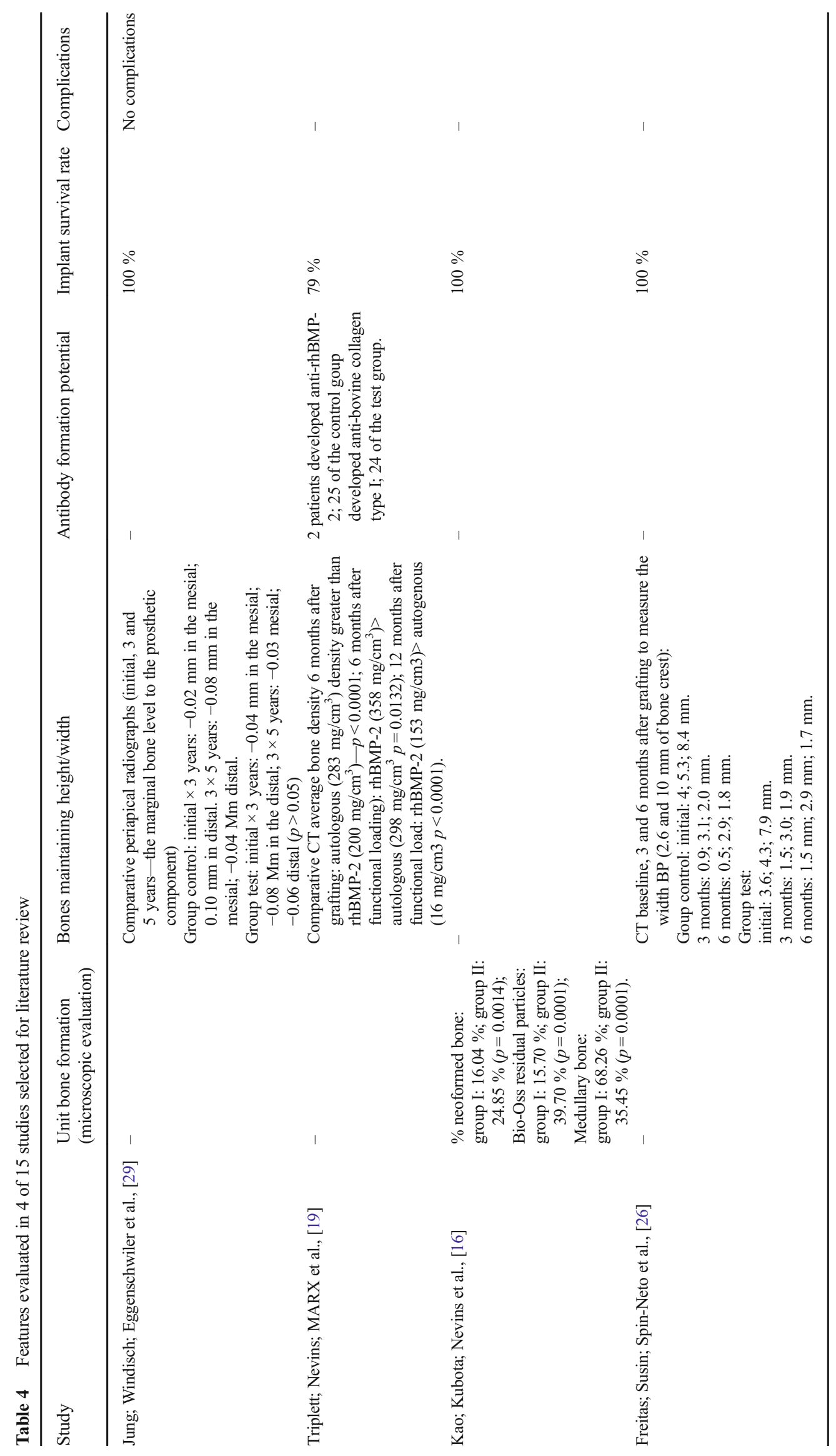




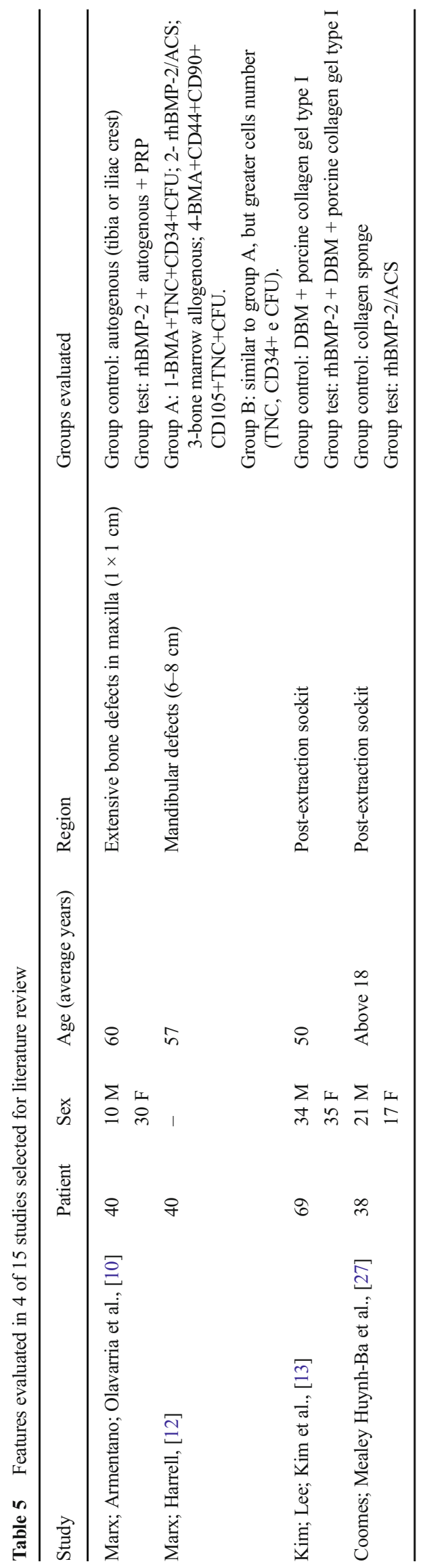

bone density, autogenous bone superiority was observed at 6 months after grafting with autogenous bone or rhBMP-2/ ACS, while the density values at 6 and 12 months after functional loading were significant higher in the rhBMP-2 group compared with the autogenous bone graft group $(p<0.05)$ [19]. Therefore, in these situations, it may be concluded the BMP causes an increase in the density of the neoformed bone over time, which leads to a more positive prognosis of rehabilitative treatment with implants. Despite the osteogenic, osteoconductive, and osteoinductive properties of autogenous bone, its application in the maxillary sinus promotes, beyond bone apposition, remodeling over time. The results of the studies reviewed here indicated increased remodeling with autogenous bone grafts compared to rhBMP-2 [14-16, 19].

The combination of osteoconductive bone substitutes with rhBMP-2 for the elevation of the sinus membrane is probably not necessary. In a clinical trial involving 22 patients who underwent elevation of the sinus membrane and received grafts with either rhBMP-2/Bio-Oss ${ }^{\circledR}$ in a $4: 1$ ratio or only Bio-Oss ${ }^{\circledR}$, the percentage of neoformed bone was greater in the group treated with Bio-Oss ${ }^{\circledR}$, which confirms our previous statement. These results may be attributed to an increase in osteoclast differentiation caused by the release of rhBMP-2 [16], which also promotes increased regulation of the activator receptor of the nuclear factor-kappa B (NF-kB), the main factor responsible for osteoblast differentiation and a very important factor for osteoinduction. Interactions between the components of osteoclastogenesis and osteoblastogenesis are influenced by the behavior of rhBMP-2. The activation of the receptor activator of nuclear factor Kappa-B ligand (RANKL) and osteoprotegerin (OPG) systems at the same time by rhBMP-2 by negative feedback mechanisms leads to an increase or decrease of the bone mass. This interaction complex is based on the interactions in the central signaling pathway in bone remodeling [30].

The greatest obstacle for maxillary bone reconstruction is certainly the availability of bone for achieving satisfactory repair in case of extensive damage. Such defects have been treated with autogenous block grafts harvested from the oral cavity (mental region and mandibular ramus); for the treatment of total maxillary defects, extraoral donor regions such as the cranial vault, iliac crest, tibia, fibula, ribs, radius, and ulna are used. However, surgical morbidity associated with the necessity of a secondary donor site as well as the contraindication for general anesthesia in systemically compromised patients makes the search for other alternatives a subject for further research.

In a clinical trial involving the study of 40 patients with

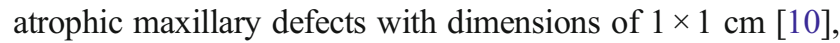
there were no differences in terms of the area of the neoformed bone between the control (autogenous bone; tibia or iliac crest) and test (rhBMP-2 + allograft bone + PRP) groups $(p=0.95)$, which indicated the similar 


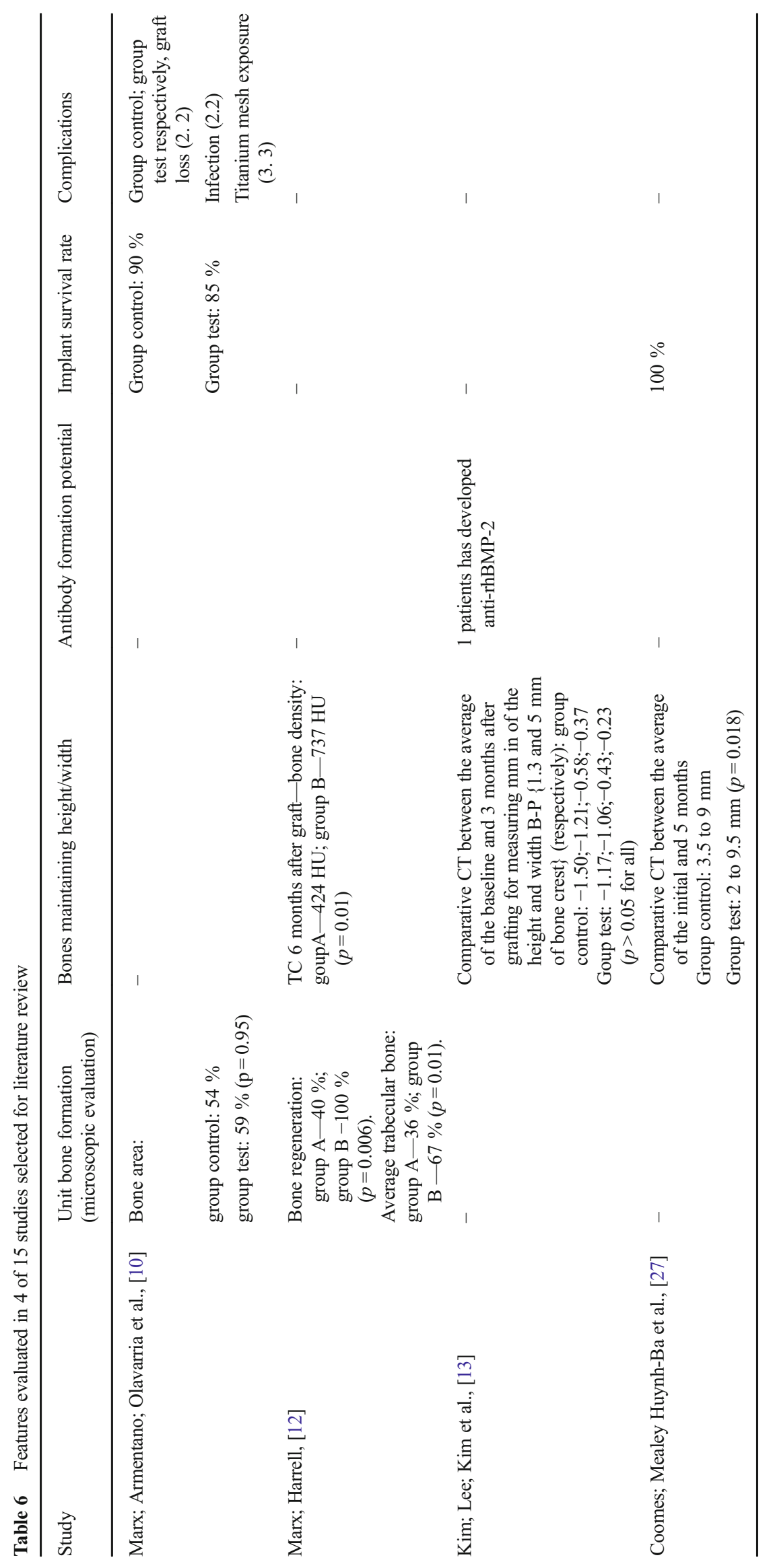


efficacies of the two graft treatments. Two cases in each group experienced early titanium mesh exposure, initially related to the lack of vascularization in the graft, leading to the loss of those four grafts. Additionally, late mesh exposure occurred in three cases in each group; however, since the grafts had by then vascularized, the sites were successfully sutured, thus explaining the absence of infection or graft loss.

In terms of bone reconstruction, mandibular defects still represent a challenging situation for maxillofacial surgeons. Mandibular defects result from high impact facial traumas that cause extensive damage and subsequent resorption as well as from bone resection caused by pathological lesions [31]. Unfortunately, for graft reconstruction, free autogenous graft is not a favorable alternative in most of these cases. In such situations, microvascularized grafts are the best option for treatment. However, the presence of a highly specialized multidisciplinary team is vital for the removal of the microvascularized graft, which, in addition to surgical morbidity, hampers the implementation of this approach.

A recently published study involving 40 patients with large mandibular defects $(6-8 \mathrm{~cm})$ reported that reconstruction with rhBMP-2/ACS in association with bone marrow aspirates and undifferentiated mesenchymal cells (including tenascin-C (TNC), CD34 $4^{+}$, and CFU) 6 months after grafting resulted in a favorable bone density for implant installation (737 Hounsfield units [HU]: measure unit for radiodensity used in computed tomoghraphic scans). TNC represents the total nucleated cells in the bone marrow aspirate; CD34 is a hematopoietic progenitor cell antigen, which represents a protein encoded by the $C D 34$ gene, expressed in the early hematopoietic and vascular-associated tissues; $\mathrm{CFU}$ is the number of colony-forming units of $\mathrm{CD}^{+}$cells - a measure of the number of $\mathrm{CD} 34^{+}$cells in the bone marrow aspirate. These results are encouraging since they indicate a viable alternative for large reconstructions. Despite this body of results obtained from randomized clinical trials, which are considered highly reliable in terms of scientific evidence, there is still a necessity for further studies on this subject in order to evaluate the concentration of the osteoprogenitor cells and extent of clinical tolerance, as well as to perform long-term monitoring after functional loading.

Despite the high success rates of rhBMP-2 application, the development of immunological factors such as anti-rhBMP-2, anti-bovine collagen type I, and anti-human collagen type I antibodies needs to be considered. These factors could potentially affect the safety and efficacy of rhBMP-2. However, the risks of immune system interactions involving rhBMP-2 seem to be low $[13,29]$. Therefore, further evaluation of the production of antibodies in response to rhBMP-2 should be performed to monitor the long-term safety of rhBMP-2 application.

\section{Conclusions}

Based on the results of our review of clinical studies involving the use of rhBMP2 in dentistry, it was concluded the following that:

1. The use of rhBMP-2/ACS for the preservation of the alveolar ridge after tooth extraction or for increasing the local defects is safe and viable.

2. The use of rhBMP-2/Bio-Oss ${ }^{\circledR}$ in maxillary sinus membrane elevation is unnecessary. It can, however, improve and accelerate the maturation process in cases of guided bone regeneration in the treatment of peri-implant defects. However, the use of rhBMP-2 for long-term bone maintenance is unnecessary.

3. Compounds comprising rhBMP-2, allogenic bone, and PRP might act as substitutes for autogenous grafts in maxillary critical defects.

4. In large mandibular defects $(6-8 \mathrm{~cm})$, the use of rhBMP2/ACS, bone marrow aspirates, and undifferentiated mesenchymal cells together results in favorable bone density for implant installation.

\section{References}

1. Urist MR (1965) Bone: formation by autoinduction. Science 150: 893-899

2. Urist MR, Mikulski A, Lietze A (1979) Solubilized and insolubilized bone morphogenetic protein. Proc Natl Acad Sci U S A 76:1828-1832

3. Wozney JM, Rosen V, Celeste AJ, Mitsock LM, Whitters MJ, Kriz RW et al (1988) Novel regulators of bone formation: molecular clones and activities. Science 242:1528-1534

4. Bentz H, Nathan RM, Rosen DM, Armstrong RM, Thompson AY, Segarini PR et al (1989) Purification and characterization of a unique osteoinductive factor from bovine bone. J Biol Chem 264: 20805-20810

5. Wozney JM (2002) Overview of bone morphogenetic proteins. Spine (Phila Pa 1976) 27:S2-S8

6. Friess W, Uludag H, Foskett S, Biron R, Sargeant C (1999) Characterization of absorbable collagen sponges as rhBMP-2 carriers. Int J Pharm. Netherlands:91-99.

7. Uludag H, Gao T, Porter TJ, Friess W, Wozney JM (2001) Delivery systems for BMPs: factors contributing to protein retention at an application site. J Bone Joint Surg Am 83-A(Suppl 1):S128-S135

8. Valentin-Opran A, Wozney J, Csimma C, Lilly L, Riedel GE (2002) Clinical evaluation of recombinant human bone morphogenetic protein-2. Clin Orthop Relat Res:110-120.

9. Geiger M, Li RH, Friess W (2003) Collagen sponges for bone regeneration with rhBMP-2. Adv Drug Deliv Rev. Netherlands: 1613-1629.

10. Marx RE, Armentano L, Olavarria A, Samaniego J (2013) rhBMP2/ACS grafts versus autogenous cancellous marrow grafts in large vertical defects of the maxilla: an unsponsored randomized openlabel clinical trial. Int J Oral Maxillofac Implants 28:e243-e251

11. Burkus JK, Gornet MF, Dickman CA, Zdeblick TA (2002) Anterior lumbar interbody fusion using rhBMP-2 with tapered interbody cages. J Spinal Disord Tech 15:337-349 
12. Marx RE, Harrell DB (2014) Translational research: The CD34+ cell is crucial for large-volume bone regeneration from the milieu of bone marrow progenitor cells in craniomandibular reconstruction. Int J Oral Maxillofac Implants 29(2):e201-e209

13. Kim YJ, Lee JY, Kim JE, Park JC, Shin SW, Cho KS (2014) Ridge preservation using demineralized bone matrix gel with recombinant human bone morphogenetic protein-2 after tooth extraction: a randomized controlled clinical trial. J Oral Maxillofac Surg 72(7): $1281-1290$

14. Boyne PJ, Marx RE, Nevins M, Triplett G, Lazaro E, Lilly LC, Alder M, Nummikoski P (1997) A feasibility study evaluating rhBMP-2/absorbable collagen sponge for maxillary sinus floor augmentation. Int J Periodontics Restorative Dent 17(1):11-25

15. Boyne PJ, Lilly LC, Marx RE, Moy PK, Nevins M, Spagnoli DB, Triplett RG (2005) De novo bone induction by recombinant human bone morphogenetic protein-2 (rhBMP-2) in maxillary sinus floor augmentation. J Oral Maxillofac Surg 63(12):1693-1707

16. Kao DW, Kubota A, Nevins M, Fiorellini JP (2012) The negative effect of combining rhBMP-2 and Bio-Oss on bone formation for maxillary sinus augmentation. Int J Periodontics Restorative Dent 32(1):61-67

17. Sharan A, Madjar D (2008) Maxillary sinus pneumatization following extractions: a radiographic study. Int J Oral Maxillofac Implants 23(1):48-56

18. LInd M, Eriksen EF, Bünger C (1996) Bone morphogenetic protein- 2 but not bone morphogenetic protein- 4 and -6 stimulates chemotactic migration of human osteoblasts, human marrow osteoblasts, and U2-OS cells. Bone 18(1):53-57

19. Triplett RG, Nevins M, Marx RE, Spagnoli DB, Oates TW, Moy PK, Boyne PJ (2009) Pivotal, randomized, parallel evaluation of recombinant human bone morphogenetic protein-2/absorbable collagen sponge and autogenous bone graft for maxillary sinus floor augmentation. J Oral Maxillofac Surg 67(9):1947-1960

20. Gamal AY, Aziz M, Salama MH, Iacono VJ (2014) Gingival crevicular fluid bone morphogenetic protein-2 release profile following the use of modified perforated membrane barriers in localized intrabony defects: a randomized clinical trial. J Int Acad Periodontol 16(2):55-63

21. Alonso N, Risso GH, Denadai R, Raposo-Amaral CE (2014) Effect of maxillary alveolar reconstruction on nasal symmetry of cleft lip and palate patients: a study comparing iliac crest bone graft and recombinant human bone morphogenetic protein-2. J Plast Reconstr Aesthet Surg 67(9):1201-1208

22. Howell TH, Fiorellini J, Jones A, Alder M, Nummikoski P, Lazaro M, Lilly L, Cochran D (1997) A feasibility study evaluating
rhBMP-2/absorbable collagen sponge device for local alveolar ridge preservation or augmentation. Int J Periodontics Restorative Dent 17(2):124-139

23. Cochran DL, Jones AA, Lilly LC, Fiorellini JP, Howell H (2000) Evaluation of recombinant human bone morphogenetic protein-2 in oral applications including the use of endosseous implants: 3-year results of a pilot study in humans. J Periodontol 71(8):1241-1257

24. Bianchi J, Fiorellini JP, Howell TH, Sekler J, Curtin H, Nevins ML, Friedland B (2004) Measuring the efficacy of rhBMP-2 to regenerate bone: a radiographic study using a commercially available software program. Int J Periodontics Restorative Dent 24(6):579-587

25. Fiorellini JP, Howell TH, Cochran D, Malmquist J, Lilly LC, Spagnoli D, Toljanic J, Jones A, Nevins M (2005) Randomized study evaluating recombinant human bone morphogenetic protein-2 for extraction socket augmentation. J Periodontol 76(4): 605-613

26. de Freitas RM, Susin C, Spin-Neto R, Marcantonio C, Wikesjö UM, Pereira LA, Marcantonio E Jr (2013) Horizontal ridge augmentation of the atrophic anterior maxilla using rhBMP-2/ACS or autogenous bone grafts: a proof-of-concept randomized clinical trial. J Clin Periodontol.

27. Coomes AM, Mealey BL, Huynh-Ba G, Barboza-Arguello C, Moore WS, Cochran DL (2014) Buccal bone formation after flapless extraction: a randomized, controlled clinical trial comparing recombinant human bone morphogenetic protein $2 /$ absorbable collagen carrier and collagen sponge alone. J Periodontol 85(4): $525-535$

28. Jung RE, Glauser R, Schärer P, Hämmerle CH, Sailer HF, Weber FE (2003) Effect of rhBMP-2 on guided bone regeneration in humans. Clin Oral Implants Res 14(5):556-568

29. Jung RE, Windisch SI, Eggenschwiler AM, Thoma DS, Weber FE, Hämmerle CH (2009) A randomized-controlled clinical trial evaluating clinical and radiological outcomes after 3 and 5 years of dental implants placed in bone regenerated by means of GBR techniques with or without the addition of BMP-2. Clin Oral Implants Res 20(7):660-666

30. Jensen ED, Pham L, Billington CJ Jr, Espe K, Carlson AE, Westendorf JJ, Petryk A, Gopalakrishnan R, Mansky K (2010) Bone morphogenic protein 2 directly enhances differentiation of murine osteoclast precursors. J Cell Biochem 109(4):672-682. doi: $10.1002 /$ jcb. 22462

31. Hayden RE, Mullin DP, Patel AK (2012) Reconstruction of the segmental mandibular defect: current state of the art. Curr Opin Otolaryngol Head Neck Surg 20(4):231-236 